\title{
OFFICIAL DOCUMENTS
}

\section{CONTENTS}

American Republics. Protocol on uniformity of Powers of Attorney which are to be utilized abroad. February $17,1940 \ldots \ldots \ldots \ldots \ldots \ldots \ldots \ldots \ldots \ldots \ldots$

Bulgaria, Hungary, Rumania-United States. Declarations of war. June 5, 1948197

Canada-United States. Convention and protocol on double taxation. March 4, 1948

Dominican Repubuic-United Stateas. Convention modifying convention of 1924 concerning collection of customs revenue. September $24,1940 \ldots \ldots \ldots \ldots \ldots 209$

France (Fighting)-United States. Mutual aid agreement. July $9,194 . \ldots \ldots 213$

Great Britain-U.S.S.R. Treaty of alliance. May $2 \theta, 1942 \ldots \ldots \ldots \ldots \ldots$

Great Britain-United States. Mutual aid agreement. Exchange of notes. Sept. $2,1942 \ldots \ldots \ldots \ldots \ldots \ldots \ldots \ldots \ldots \ldots \ldots \ldots \ldots \ldots \ldots \ldots \ldots \ldots \ldots \ldots, 219$

Australis-United States. Mutual aid agreement. Same date......... 221

New Zmaland-United States. Mutual aid agreement. Same date. . . . . 221

Mutual Aid Agrmimants. United States: Belgium, Czechoslovakia, Greece, The Netherlands, Norway, Poland, Yugoslavia.

Sweden-Unitmo States. Convention and protocol on double taxation. March 28 , 1989.

United \$тatrs. Proclamations regarding alien enemies:

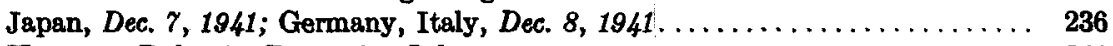

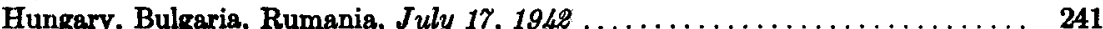

